\title{
Diffuse Cerebral Pneumocephalus
}

\author{
Ubaid Abdulla, MBBS \\ Department of Surgery \\ TU Teaching Hospital \\ Maharajgunj \\ Kathmandu, Nepal

\section{Pankaj Roy, MBBS} \\ Department of Surgery \\ TU Teaching Hospital \\ Maharajgunj \\ Kathmandu, Nepal
}

\section{Address for correspondence: \\ Ubaid Abdulla, MBBS \\ Department of Surgery \\ TU Teaching Hospital \\ Maharajgunj, Kathmandu \\ Nepal \\ Email: abdullaubaid@hotmail.com}

Received, October 2, 2004

Accepted, October 10, 2004

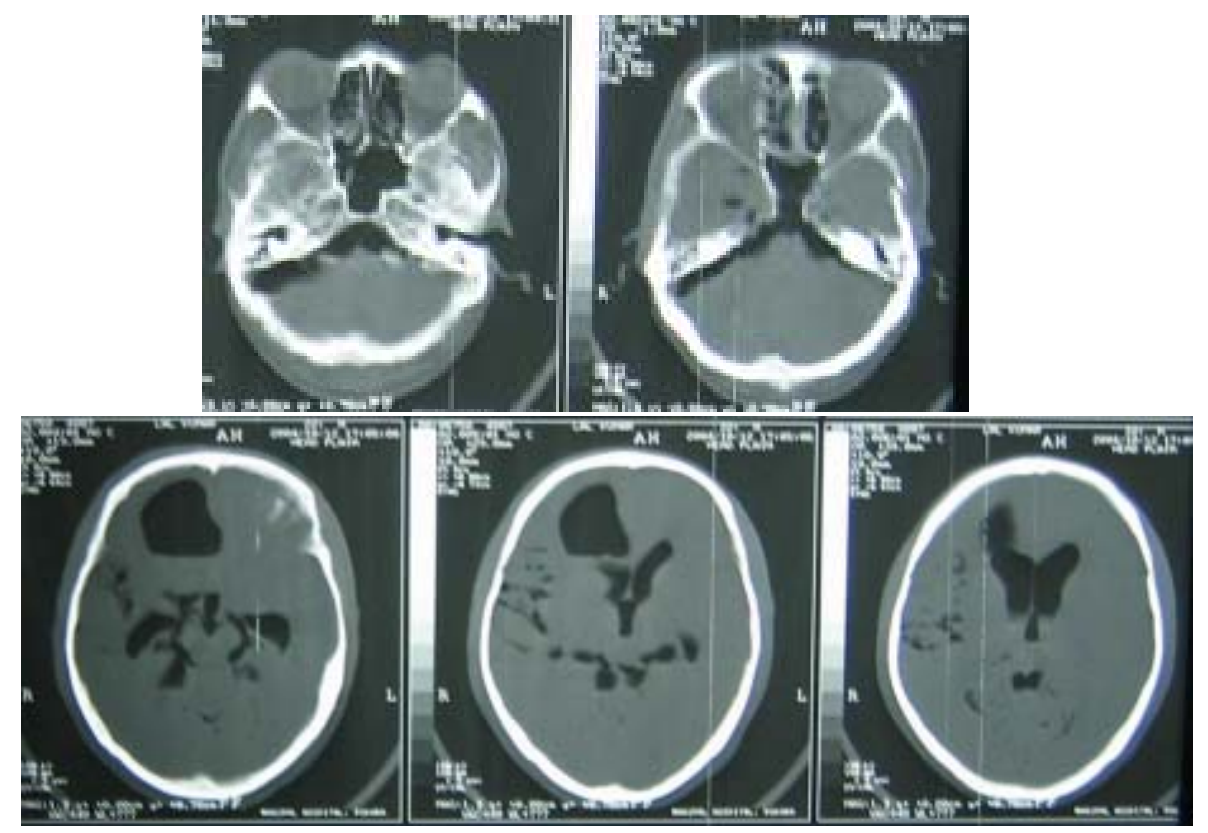

Figure 1. CT scan of head showing diffuse intracranial air. Consecutive slices show the air in all major cisterns, ventricles and subarachnoid spaces.
$\mathrm{T}$ his 40-year-old gentleman was referred to our institution following a road traffic accident 4 days prior to presentation. On examination, he had a Glasgow Coma Scale of 12/15 with no focal neurological deficits. There was no evidence of external injury. A noncontrast computed tomography (CT) scan of his head (Figure 1) was obtained emergently. It revealed widespread presence of intracranial air. Most notably air was present in the right frontal brain parenchyma, in both lateral ventricles and the third ventricle, and most of the subarachnoid spaces and cisterns ( bilateral cerebellopontile angle cisterns, perimesencephalic cisterns, quadrigeminal cisterns, right sylvian fissure, and right cortical sulci). The patient was managed conservatively with high flow oxygen and head elevation, and subsequently developed hydrocephalus and underwent placement of a ventriculaoperioneal shunt. $\mathrm{He}$ was discharged from the hospital in 20 days in a stable condition.

It is not uncommon to have some degree of intracranial air following trauma especially when skull fracture involves the sphenoid and petrous bone. ${ }^{2,3}$ However, presence of such diffuse pneumocephalus (in the brain parenchyma, most of the subarachnoid cisterns and in the ventricles) in one patient is extremely rare. The most common location of intracranial air is the subarachnoid space. ${ }^{2}$ Sometimes the patient can present with a rapid neurological deterioration due to tension pneumocephalus. ${ }^{1}$ Presence of multiple air bubbles is associated with a bad prognosis. ${ }^{3}$ The air in our case was mostly likely sucked in from the frontal sinus through the fracture of the anterior cranial fossa.

\section{References}

1. Gonul E, Izci Y, Sali A, et al: Subdural and intraventricular traumatic tension pneumocephalus: case report. Minim Invasive Neurosurg 43:98-101, 2000

2. Shuto T, Kitsuta Y, Yoshida T, et al: Clinical study on intracranial air in the severe head injury. No To Shinkei 51:615-619, 1999 (Jpn)

3. Steudel WI, Hacker H: Prognosis, incidence and management of acute traumatic intracranial pneumocephalus. A retrospective analysis of 49 cases. Acta Neurochir (Wien) 80:93-99, 1986 